\title{
Combined effects of inorganic nutrients and organic enrichment on intertidal benthic macrofauna: an experimental approach
}

\author{
Jayne E. Fitch*, Tasman P. Crowe \\ School of Biology and Environmental Science, Science Centre West, University College Dublin, Belfield, Dublin 4, Ireland
}

\begin{abstract}
Marine environments are affected by multiple anthropogenic stressors, but research to date has focussed primarily on the impacts and indicators of individual stressors. Nutrient and organic enrichment can occur separately or in combination with each other, but their combined effects are not fully understood. In a field experiment on a sheltered, sandy-mud, sedimentary intertidal shore, 3 levels of inorganic nutrient addition (nutrient sticks) were crossed with 2 levels of organic matter enrichment (rusks), and benthic macrofauna were sampled at 2 times. Organic matter caused greater impacts on benthic macrofauna than nutrients and had a significant effect on taxon richness and Shannon diversity. Total abundance responded to the interactive effects of nutrients and organic matter. The response observed in total abundance was largely driven by the small opportunistic polychaete Capitella sp., which responded primarily to organic matter, but its response was mediated by addition of nutrients to the system. This highlights that its abundance varies in response to interactions among stressors, so cannot be easily interpreted. The performance of 2 biotic indices, the AZTI Marine Biotic Index (AMBI) and Multivariate AMBI (M-AMBI), varied, but M-AMBI proved to be the most effective at detecting the combined effects of nutrients and organic enrichment. These findings show that effective management of coastal environments must take account of the potentially complex combined effects of multiple stressors.
\end{abstract}

KEY WORDS: Multiple stressors · Inorganic nutrients · Organic matter · Benthic $\cdot$ Intertidal Macrofauna Resale or republication not permitted without written consent of the publisher

\section{INTRODUCTION}

Many marine ecosystems are exposed simultaneously to multiple anthropogenic stressors (IbarraObando et al. 2004, Crain et al. 2008, Halpern et al. 2008, Ban et al. 2010). The combined effects of any 2 or more stressors can be additive (equal to the sum of the individual effects of the stressor), synergistic (greater than the individual effects of the stressors) or antagonistic (less than the individual effects) (Folt et al. 1999), and such interactions may be complex and context-dependent. Despite increasing interest in the effects of multiple stressors in marine ecosystems, the majority of studies to date have focussed on individual effects of single stressors (Crain et al. 2008, Ban et al. 2010). Prediction of the additive effects of multiple stressors can be made from studying individual stressors, but understanding the potential interactive effects of multiple stressors is limited (Ban et al. 2010). There is a pressing need to quantify causal links between multiple anthropogenic stressors and biological responses to permit the effective targeting of management in marine ecosystems (Adams 2005, Claudet \& Fraschetti 2010).

Eutrophication has been identified as one of the greatest threats to European regional seas (Maloney 1996), and the impacts of eutrophication have been documented in a wide range of coastal ecosystems and taxonomic groups (e.g. Sturgis \& Murray 1997, Lopez et al. 1998, Rossi \& Underwood 2002, 
McClanahan et al. 2005, Larson et al. 2007, Sundbäck et al. 2007, Petersen et al. 2009). Inorganic nutrients and organic matter are 2 of the most important stressors affecting aquatic ecosystems and can lead to eutrophication (O'Gorman et al. 2012). Nutrients can stimulate primary producers such as macroand microalgae and can increase microphytobenthic production, reducing competition for food resources, and can lead to hypoxia and chemical changes in the sediments (Sundbäck \& Snoeijs 1991, Gray et al. 2002, Sundbäck et al. 2010). Nutrient enrichment is often accompanied by, or can lead to, following the accelerated growth of primary producers, organic enrichment. The response of benthic macrofauna to organic enrichment has been extensively characterised in the literature, with many studies supporting the pattern of succession described by Pearson \& Rosenberg (1978) (e.g. Vetter 1995, Ceccherelli \& Cinelli 1997, Gray et al. 2002, Rossi 2003, Bouchet \& Sauriau 2008).The chemical, physical and biological effects that occur as a result of nutrient and organic enrichment are not due to inputs of nitrogen and carbon alone. Phosphorus, sulphides and ammonia can affect algal and faunal communities in a variety of ways, including increased growth or varying levels of toxicity, particularly to molluscs (Gray et al. 2002). Whilst both stressors are nutrient-based and their individual effects are well characterised, the results of some studies indicate that nutrient and organic matter can have interactive effects (McClanahan et al. 2005, Carreiro-Silva et al. 2009, Fitch \& Crowe 2010, O'Gorman et al. 2012). It is therefore important to investigate the potential impacts of these stressors in combination and to test the suitability of monitoring tools to predict these effects (Fitch \& Crowe 2010, 2011, O'Gorman et al. 2012).

The European Water Framework Directive (WFD, 2000/60/EC) and the Marine Strategy Framework Directive (MSFD, 2008/56/EC) provide a basis for the protection of marine waters belonging to member states of the European Union. A key aim of the WFD is for all estuarine and coastal water bodies (up to $1 \mathrm{~km}$ offshore) to achieve at least 'Good' ecological status (ES) by 2015. The MSFD concerns subtidal marine waters and recognises that fauna inhabiting the seafloor can be useful in the assessment of ecosystem health, and the assessment of proportions of sensitive and opportunistic taxa is supported (Rice et al. 2012).

The assessment of the ES of each water body under the WFD is based on chemical, physical and biological parameters, and each area has been, or will be, assigned 1 of the 5 levels of ES set out under the WFD: High (biological conditions associated with no or very low human pressure, also known as reference conditions), Good (slight deviation from reference conditions), Moderate (moderate deviation from reference conditions), Poor (major deviation from reference conditions) or Bad (severe alterations from reference conditions). Benthic macrofauna are one of the biological components considered by the WFD. Benthic macrofauna have been used as indicators of habitat quality for many years and are particularly suitable due to the well-characterised response to anthropogenic disturbance such as eutrophication and dredging they exhibit (Bustos-Baez \& Frid 2003, Diaz et al. 2004, Dauvin 2007, Dauvin et al. 2010). Several biotic indices have been proposed for assessing ES under the WFD using benthic macrofauna (e.g. Borja et al. 2000, Simboura \& Zenetos 2002, Rosenberg et al. 2004, Dauvin \& Ruellet 2007, Muxika et al. 2007a), and they offer the advantage of condensing often large datasets that arise from benthic sampling programmes into a single value (Fleischer et al. 2007).

The AZTI Marine Biotic Index (AMBI) analyses the proportion of taxa assigned to each of 5 ecological groups (Sensitive to Opportunistic, see www.azti.es) and is the most widely used biotic index under the WFD (Borja et al. 2000, 2009b, Muxika et al. 2007a). It is used in its own right in 13 countries to indicate the proportion of disturbance to sensitive taxa and has also been incorporated into multivariate and multimetric indices such as Multivariate AMBI (MAMBI) and the Infaunal Quality Index (IQI) (Borja et al. 2009a). M-AMBI, which is based on AMBI and also incorporates measures of richness and Shannon diversity, has been shown to be effective in coastal waters and is also being developed for use in estuarine and intertidal waters (Borja et al. 2009a). AMBI and M-AMBI have been shown to respond to a variety of anthropogenic pressures including hypoxia, eutrophication, oil platform discharges, dredging and fish aquaculture (Borja et al. 2003, 2006, 2009b, Muxika et al. 2005, Callier et al. 2009), and have been globally validated in different habitats and inter-calibrated with other methodologies (Borja et al. 2007, 2008, Ruellet \& Dauvin 2007, Blanchet et al. 2008, Bouchet \& Sauriau 2008). However, few studies have tested indices experimentally and to our knowledge none have evaluated their sensitivity to the impacts arising from simultaneous inputs of multiple stressors (but see Callier et al. 2009).

Recent work has shown that these particular indices may be effective at detecting changes in ES in response to anthropogenic stressors in intertidal habitats (Blanchet et al. 2008, Bouchet \& Sauriau 2008, Fitch \& Crowe 2010), which would provide a 
cost-effective and valuable additional tool to subtidal monitoring. However, intertidal soft sediments often support macrofaunal communities with low species numbers, low diversity and low abundance, which can lead to an unsatisfactory estimation of ES (Dauvin et al. 2007). Furthermore, ecological indices that are based on the relative abundance of different taxa have been shown to be over-sensitive to high abundances of one or a few dominant taxa (Dauvin et al. 2010, Warwick et al. 2010).

The present study aimed to disentangle potential interactive effects of inorganic nutrients and organic matter on intertidal benthic macrofauna and to test the sensitivity of the AMBI and the M-AMBI to detect responses to multiple stressors.

\section{MATERIALS AND METHODS}

\section{Study area and experimental design}

The experimental site was a sheltered intertidal soft sediment bay (Finavarra) in Galway Bay (Ireland). The experiment was set up along the midshore where sediments were characterised by muddy sands. Lug worm Arenicola marina casts and cockles Cerastoderma edule were observed in high numbers across the shore. Due to the very shallow shore profile, all experimental plots were exposed within 10 min during low tide. Previous studies of the site identified the most numerically dominant taxa to be soft-bodied polychaetes such as Arenicola marina, Scoloplos armiger and Pygospio elegans, the oligochaete Tubificoides benedii, the bivalve molluscs Angulus tenius and Macoma balthica and amphipods from the family Haustoriidae (Fitch \& Crowe 2010). The shore was sheltered from 3 sides by land and at the seaward side was protected by a land spit. The shore was assigned Good ES with AMBI and High ES with M-AMBI, surface water had a salinity of 35 and low nutrient levels (dissolved inorganic nitrogen: $0.3 \mathrm{mg} \mathrm{l}^{-1}$ ), and there was a moderate organic matter content $(1.7 \%)$ in sediments that were dominated by very fine sand (Fitch \& Crowe 2010).

Tidal inundation was via a narrow channel (50 m wide) running parallel with the shore, where fast currents were observed and sandy coarse sediments were interspersed with the tube-building polychaete Lanice conchiliga.

Three levels of nutrient addition $(0,100$ and $200 \mathrm{~g}$ $\mathrm{m}^{-2}$ per dose, or ambient $(=\mathrm{N})$, medium $(+\mathrm{N})$ and high $(++\mathrm{N})$ respectively) were crossed with 2 levels of organic matter (0 and $200 \mathrm{~g} \mathrm{~m}^{-2}$ per dose, or ambient
$(=\mathrm{OM})$ and addition (+OM) respectively). Inorganic nutrients were added as slow-release 'house plant food' fertiliser sticks (BabyBio, NPK 10:6:10), which were approximately $6 \mathrm{~cm}$ long and $1 \mathrm{~cm}$ in diameter (O'Gorman et al. 2012). Fertiliser sticks were pushed fully into the sediment in treatment plots. The fertiliser sticks were spaced out evenly throughout plots in an attempt to ensure even nutrient enrichment within each plot. Per-dose levels were calculated following pilot work carried out at the experimental shore prior to the commencement of the experimental study.

Organic matter was added as a high-carbohydrate energy rusk (Farley's Rusk, 80\% carbohydrates, of which $30 \%$ sugar) (Fitch \& Crowe 2011, O'Gorman et al. 2012). The rusks were broken into small (approximately $1 \times 2 \mathrm{~cm}$ ) pieces and pushed in to the sediments in treatment plots. The addition of labile carbon has been shown to stimulate microbenthic activity and cause chemical changes in sediments associated with organic enrichment such as increased sulphate production (Koch et al. 2007). Procedural controls designed to mimic the physical disturbance caused during treatment application were applied, using a $1 \mathrm{~cm}$ diameter plastic cylinder, to additional plots for 3 of the treatments: high and medium nutrient addition and organic matter addition.

The experiment was set up in June 2007. Two sampling times were planned (after 3 and $11 \mathrm{mo}$ ), and for each sampling time, 4 replicate plots were randomly assigned to each treatment and 3 were assigned to each procedural control prior to the start of the experiment. Sixty-six plots $(50 \times 50 \mathrm{~cm})$ were therefore marked, at least $5 \mathrm{~m}$ apart to ensure independence, and treatments and sampling times were randomly assigned. Plots were treated at $14 \mathrm{~d}$ intervals for the first 3 mo and at $30 \mathrm{~d}$ intervals thereafter until the end of the experiment.

\section{Data collection}

The treatments applied were intended to artificially create conditions comparable with thresholds of chemical status under the WFD. High and Bad threshold values for ammonia and nitrate chemical status are given in Table 1 (Bald et al. 2005, Loureiro et al. 2006).

To test the effectiveness of the nutrient-enrichment protocol, nitrate and ammonia levels were measured for each treatment in surface water pools and in pore water at low tide. Samples were taken from 2 random plots in each treatment, $1 \mathrm{~d}$ after treatment applica- 
Table 1. Threshold values for the chemical variables ammonia $\left(\mathrm{NH}_{4}\right)$ and nitrate $\left(\mathrm{NO}_{3}\right)$ and reference conditions for taxon richness $(S)$, Shannon diversity $\left(H^{\prime}\right)$ and the AZTI Marine Biotic Index (AMBI) that were used to calculate Multivariate AMBI (M-AMBI) ecological quality ratio (EQR) (data derived from Fitch \& Crowe 2010). 'High' and 'Bad' refer to ecological status (ES) assigned under the Water Framework Directive

\begin{tabular}{|lccccc|}
\hline ES & $\begin{array}{c}\text { Ammonia } \\
\left(\mu \mathrm{mol} \mathrm{l^{-1 } )}\right.\end{array}$ & $\begin{array}{c}\text { Nitrate } \\
\left(\mu \mathrm{mol} \mathrm{l} \mathrm{l}^{-1}\right)\end{array}$ & $S$ & $H^{\prime}$ & AMBI \\
\hline High & $<2.5$ & $<5.0$ & $\begin{array}{c}14 \\
0\end{array}$ & $\begin{array}{c}2.43 \\
0\end{array}$ & $\begin{array}{c}2.45 \\
6\end{array}$ \\
Bad & $>15.5$ & $>12.9$ & 0 & & \\
\hline
\end{tabular}

tion, on 6 separate occasions over the entire experimental run. Surface water was collected using a $50 \mathrm{ml}$ syringe. Pore water was taken from the top $8 \mathrm{~cm}$ of the sediment using a syringe and pipette end (Nayar et al. 2006, Jones \& Frid 2009). The pipette end was sealed and small openings made along the length of the shaft to allow pore water to be drawn into the syringe from sedimentary interstitial space. After passing through a $45 \mu \mathrm{m}$ filter, water samples were analysed for nitrate and ammonia using a Latchet flow through auto analyser (QuickChem 8500).

Organic matter content of the sediments was sampled from 3 random plots in each treatment at the same time as the last water samples for nutrient levels (at the end of the experiment). A sediment core of $2 \mathrm{~cm}$ diameter and $5 \mathrm{~cm}$ depth was taken $(\mathrm{n}=3)$. Samples were homogenised and a subsample taken and dried at $60^{\circ} \mathrm{C}$ for $24 \mathrm{~h}$ (or until dry, determined through 2 successive measurements of equal mass). Loss on ignition of organic carbon was calculated as a percentage mass after combustion at $450^{\circ} \mathrm{C}$ for 360 min (HiMOM 2005).

In September 2007 and May 2008, plots were destructively sampled for macrofauna. In each $0.25 \mathrm{~m}^{2}$ plot, 1 replicate core $(10 \mathrm{~cm}$ diameter and $20 \mathrm{~cm}$ depth) was taken haphazardly and passed over a $0.5 \mathrm{~mm}$ mesh to retain macrofauna. Macrofauna were fixed and preserved in $10 \%$ buffered formaldehyde with Rose Bengal stain and returned to the laboratory for sorting, identification and counting. Identification was carried out to the lowest possible taxonomic level; where specimens were damaged, identification was to genus or family level.

\section{Data analyses}

Univariate measures of taxon richness $(S)$ and Shannon diversity $\left(H^{\prime}\right)$, total abundance $(N)$ and abundance of individual taxa were analysed with 3factor ANOVAs in which Time ( 3 and $11 \mathrm{mo}$ ) was random and orthogonal, Nutrients $(=\mathrm{N},+\mathrm{N}$ and $++\mathrm{N})$ was fixed and orthogonal and Organic matter (=OM and $+\mathrm{OM}$ ) was fixed and orthogonal. Cochran's test was used to test homogeneity of variance. Any interaction involving Time that was non-significant $(p \geq 0.25)$ was pooled (Underwood 1997). Differences among significant terms were identified using Student-NewmanKeuls (SNK) tests. Computations were done using GMAV5 (Underwood \& Chapman 1998).

Procedural controls to test for artefacts in response to disturbance associated with treatment application were analysed with 3-factor ANOVAs in which Time ( 3 and $11 \mathrm{mo}$ ) was random and orthogonal, and Treatment $(=\mathrm{N}+\mathrm{OM},+\mathrm{N}=\mathrm{OM}$, and $++\mathrm{N}=\mathrm{OM})$ and Procedure (unmanipulated control, procedural control and treatment) were fixed and orthogonal.

\section{Biotic indices}

Two indices were tested in the present study for their sensitivity to detect the responses of intertidal macrofaunal communities to the combined effects of inorganic nutrients and organic enrichment: the AMBI (Borja et al. 2000) and the M-AMBI (Muxika et al. 2007a) (both indices were calculated with AMBI version 4.1, http://ambi.azti.es). The ecological quality ratio (EQR) for M-AMBI was calculated using reference conditions derived from Fitch \& Crowe (2010) (Table 1), in which the experimental shore (Finavarra) was previously sampled as part of a baseline study and which found it to be one of the least polluted sites in the region. Each index was calculated for each experimental plot and these values were used as replicates in 3-factor ANOVAs based on the model described above. AMBI scores and MAMBI EQRs were translated into 1 of 5 ES categories used under the WFD (Borja et al. 2009a) (see Table 2 for boundaries used).

\section{RESULTS}

\section{Effectiveness of treatments and evaluation of artefacts}

The addition of medium $\left(100 \mathrm{~g} \mathrm{~m}^{-2}\right)$ and high $(200 \mathrm{~g}$ $\mathrm{m}^{-2}$ ) levels of inorganic nutrients were effective in raising mean levels of ammonia in surface and pore water over the experimental run $\left(F_{2,12}=5.07, \mathrm{p}<0.05\right.$ and $F_{2,12}=2.90, \mathrm{p}<0.05$ respectively) (Table 3 ). 
Whilst chemical status cannot be inferred, mean levels of ammonia in surface water were within threshold levels for High chemical status in ambient (control) plots. Levels of ammonia in organic matter addition, medium nutrient addition, medium nutrients with organic matter addition and high nutrients with organic matter addition treatments were between the thresholds for High and Bad chemical status. Levels of ammonia in surface water in high nutrient addition treatments exceeded the threshold for Bad chemical status (Tables $2 \& 3$ ).

In surface water, a large increase in nitrate was observed in ambient nutrient plus organic matter treatments (Table 3).

Despite the fact that $400 \mathrm{~g} \mathrm{~m}^{-2}$ of organic matter was added every month, which is equivalent to

Table 2. Threshold values separating the 5 ecological statuses (ES) under the Water Framework Directive for the AZTI Marine Biotic Index (AMBI) according to Borja et al. (2000) and Multivariate AMBI (M-AMBI) according to Muxika et al. (2007a)

\begin{tabular}{|lcc|}
\hline ES & AMBI & M-AMBI \\
\hline High & $<1.2$ & $>0.85$ \\
Good & $>1.2$ to $<3.3$ & $>0.55$ to $<0.85$ \\
Moderate & $>3.3$ to $<4.3$ & $>0.39$ to $<0.55$ \\
Poor & $>4.3$ to $>5.5$ & $>0.20$ to $<0.39$ \\
Bad & $>5.5$ & $<0.20$ \\
\hline
\end{tabular}

Table 3. Mean ammonia and nitrate concentrations $( \pm \mathrm{SE})$ measured in surface water and pore water for each experimental treatment. Measures were taken from 4 random plots $1 \mathrm{~d}$ after treatment application on 6 separate occasions over the course of the experiment $(n=24)$. Nutrient addition was at 0,100 or $200 \mathrm{~g} \mathrm{~m}^{-2}$ per dose, or ambient $(=\mathrm{N})$, medium $(+\mathrm{N})$ or high $(++\mathrm{N})$ respectively. Organic matter addition was at 0 or $200 \mathrm{~g} \mathrm{~m}^{-2}$ per dose, or ambient (=OM) or addition (+OM) respectively

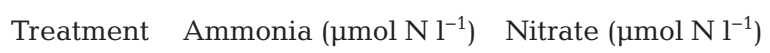

\begin{tabular}{lrr}
\hline Surface water & & \\
$=\mathrm{N}=\mathrm{OM}$ & $2.4 \pm 0.1$ & $0.0 \pm 0.00$ \\
$=\mathrm{N}+\mathrm{OM}$ & $5.9 \pm 0.1$ & $11.3 \pm 0.60$ \\
+N $=\mathrm{OM}$ & $9.0 \pm 0.5$ & $0.7 \pm 0.01$ \\
+N +OM & $4.1 \pm 0.6$ & $0.0 \pm 0.00$ \\
++N =OM & $14.0 \pm 0.5$ & $0.8 \pm 0.02$ \\
++N +OM & $5.0 \pm 0.2$ & $0.2 \pm 0.01$ \\
Pore water & & \\
$=\mathrm{N}=\mathrm{OM}$ & $24.6 \pm 0.1$ & $0.0 \pm 0.000$ \\
$=\mathrm{N}+\mathrm{OM}$ & $59.9 \pm 0.1$ & $1.4 \pm 0.600$ \\
+N =OM & $90.5 \pm 5.1$ & $0.0 \pm 0.000$ \\
+N +OM & $41.3 \pm 6.8$ & $1.3 \pm 0.700$ \\
$++\mathrm{N}=\mathrm{OM}$ & $144.0 \pm 54.0$ & $0.2 \pm 0.001$ \\
$++\mathrm{N}+\mathrm{OM}$ & $355.0 \pm 25.0$ & $1.6 \pm 0.010$
\end{tabular}

annual inputs in a highly productive system (e.g. Grebmeier et al. 1988), significant increases in organic carbon, as measured by loss on ignition, were not detectable (Fig. A1 in Appendix $1 ; F_{2,12}=0.64, \mathrm{p}>$ 0.05). Nevertheless, plots treated with organic matter gave off a strong sulphurous smell and were visibly darker (more anoxic) than other plots.

\section{Faunal responses}

There were no differences in taxon richness or Shannon diversity between unmanipulated controls, procedural controls or treatments (Table A1). Total abundance was greater in treated plots than in procedural controls or unmanipulated controls, which were not different from each other (Table A2 in Appendix 1), indicating no procedural artefacts of the experimental treatments.

A total of 7257 individuals from 27 taxa were identified (Table A2). Polychaete worms were the most common group represented in the 10 most numerically abundant taxa, with 5 taxa being identified: Capitella sp., Scoloplos armiger, Pygospio elegans, Eteone foliosa and individuals from the Spionidae family. Nematode worms and the oligochaete Tubificoides benedii represented 2 of the top 3 most abundant taxa. Other classes represented in the most numerically abundant taxa were Gastropoda, by the mud snail Hydrobia ulvae; Bivalvia, by the edible cockle Cerastoderma edule; and Malacostraca, by the brown shrimp Crangon crangon. Taxon richness (Fig. 1a,b) and Shannon diversity (Fig. 2a,b) were significantly reduced by the addition of organic matter (Table 4). This pattern of significantly reduced levels of taxon richness and Shannon diversity in organic matter treatments is consistent with significant negative responses of both AMBI and M-AMBI in assigning ES (see 'Biotic indices' below). Taxon richness and Shannon diversity significantly increased over time from the 3 to 11 mo sampling periods (Table 4, Figs. 1a,b \& 2a,b), which was consistent with significant increases in AMBI and M-AMBI scores with time from 3 to 11 mo (see Table 5). Total abundance was significantly affected by the combined influence of organic matter and nutrients (Table 4). Total abundance increased with the addition of organic matter in ambient and high nutrient treatments, but not in medium nutrient treatments (SNK procedure) (Fig. 3a,b). AMBI and M-AMBI respond to the cumulative changes in the relative abundance of all taxa present, but of the 27 taxa identified, only Capitella sp. responded significantly to any treatments 


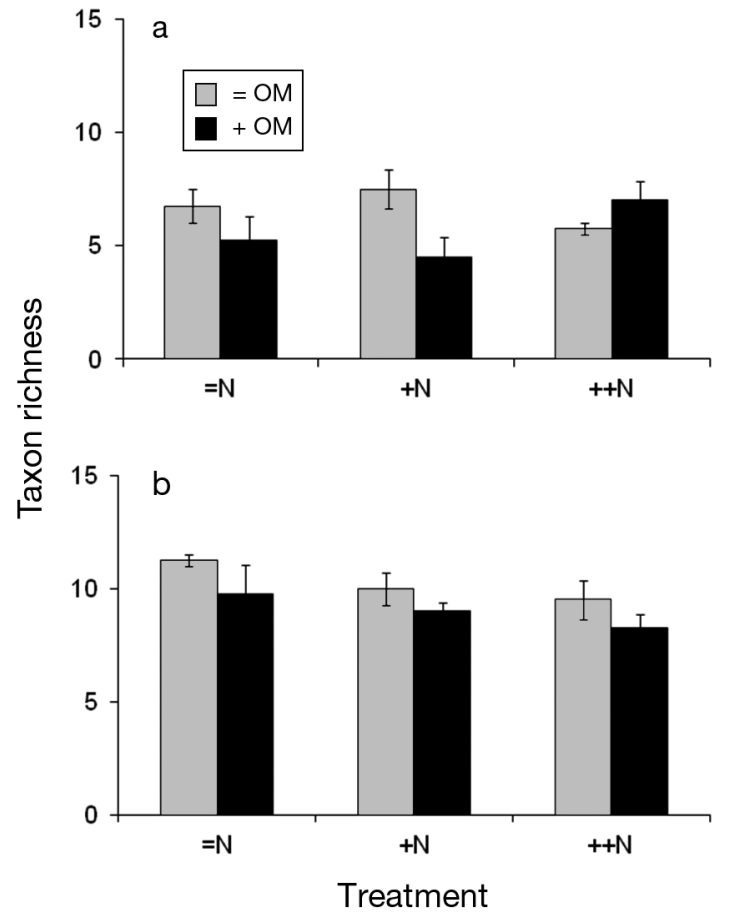

Fig. 1. Mean taxon richness $( \pm \mathrm{SE} ; \mathrm{n}=4)$ after (a) 3 mo and (b) 11 mo. See Table 3 for abbreviations

(Table 4). Abundance of Capitella sp. increased with the addition of organic matter in ambient and high nutrient treatments, but not in medium nutrient treatments (Fig. 4a,b, Table 4 ; SNK procedure).

\section{Biotic indices}

AMBI scores were significantly decreased by the addition of organic matter across all levels of nutrients

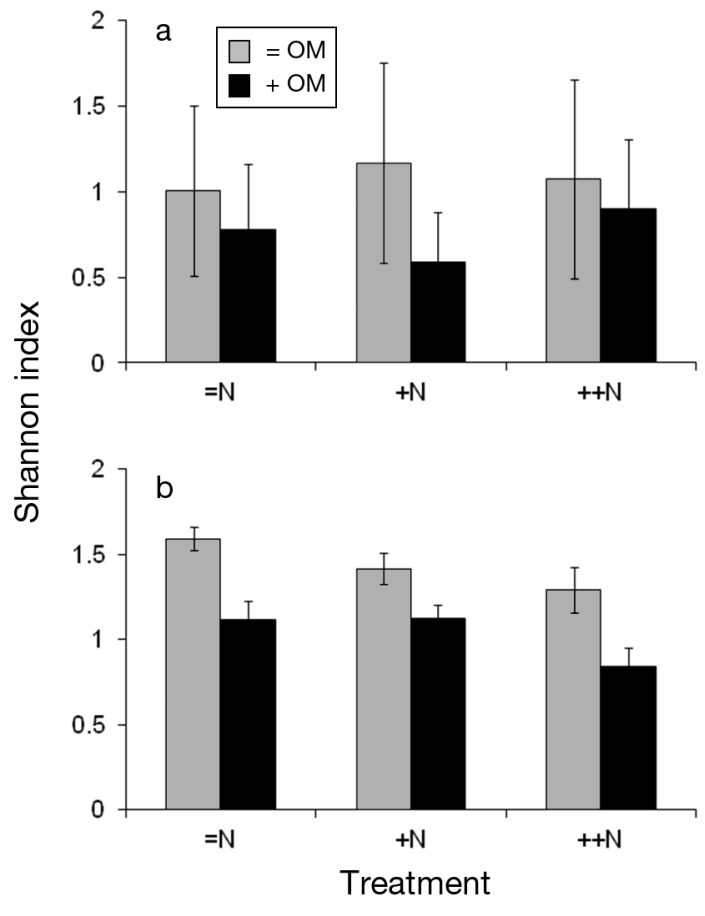

Fig. 2. Mean Shannon index $( \pm \mathrm{SE} ; \mathrm{n}=4)$ after (a) 3 mo and (b) 11 mo. See Table 3 for abbreviations

(Table 5). This was not consistently translated into changes in ES (under the WFD) in response to organic matter, as the magnitude of change, although significant, did not exceed ES boundaries in all cases. AMBI scored all treatments as having unacceptable ES after 3 and 11 mo (Table 6). The AMBI assigned all treatments a Bad ES after 3 mo (Table 6). After 11 mo, AMBI assigned Poor ES to all treatments except addition of organic matter only and addition of high levels of nutrients with organic matter, which were assigned

Table 4. ANOVAs of differences among treatments in taxon richness $(S)$ (data untransformed, Cochran's $C=0.1545, \mathrm{p}<0.05)$; Shannon index $\left(H^{\prime}\right)$ (data untransformed, Cochran's $\left.C=0.2799, \mathrm{p}<0.05\right)$; total abundance $(N)$ (data untransformed, Cochran's $C=0.2057, \mathrm{p}<0.05$ ); and abundance of Capitella sp. (data untransformed, Cochran's $C=0.1682, \mathrm{p}<0.05$ ). ${ }^{*}$ Significant at $\mathrm{p}<$ $0.05 ;{ }^{* *}$ significant at $\mathrm{p}<0.01$

\begin{tabular}{|c|c|c|c|c|c|c|c|c|c|}
\hline \multirow{2}{*}{ Source of variation } & \multirow[t]{2}{*}{$\mathrm{df}$} & \multicolumn{2}{|c|}{$-S$} & \multicolumn{2}{|c|}{$H^{\prime}-$} & \multicolumn{2}{|c|}{$N$} & \multicolumn{2}{|c|}{ Capitella sp. } \\
\hline & & MS & $F$ & MS & $F$ & MS & $F$ & MS & $F$ \\
\hline Time (Ti) & 1 & 154.08 & $67.77^{a_{1} * *}$ & 1.16 & $21.75^{\mathrm{b}, * *}$ & 147408.33 & 55.54 & 50181.33 & 37.89 \\
\hline Nutrients $(\mathrm{Nu})$ & 2 & 2.33 & $1.03^{\mathrm{a}}$ & 0.03 & 0.23 & 7525.18 & 14.99 & 2215.14 & 10.36 \\
\hline Organic matter (Om) & 1 & 18.75 & $8.25^{\mathrm{a}, *}$ & 1.16 & $30.36^{\mathrm{b}, * *}$ & 7400.33 & 1.40 & 17176.33 & 2.83 \\
\hline $\mathrm{Ti} \times \mathrm{Nu}(a)$ & 2 & 3.08 & $1.36^{\mathrm{a}}$ & 0.16 & $3.05^{\mathrm{b}}$ & 1.89 & 0.19 & 213.89 & 0.16 \\
\hline $\mathrm{Ti} \times \mathrm{Om}(b)$ & 1 & 0.00 & $0.00^{\mathrm{a}}$ & 0.01 & $0.34^{\mathrm{b}}$ & 292.00 & 1.99 & 6075.00 & 4.59 \\
\hline $\mathrm{Nu} \times \mathrm{Om}$ & 2 & 3.25 & 0.81 & 0.01 & 0.15 & 3136.52 & $119.20^{* *}$ & 1701.65 & $21.39^{*}$ \\
\hline $\mathrm{Ti} \times \mathrm{Nu} \times \mathrm{Om}$ & 2 & 4.00 & $1.76^{\mathrm{a}}$ & 0.09 & $1.83^{\mathrm{b}}$ & 26.31 & 0.01 & 79.56 & 0.94 \\
\hline Residual $(C)$ & 36 & 2.29 & & 0.05 & & 2654.29 & & 1324.45 & \\
\hline
\end{tabular}




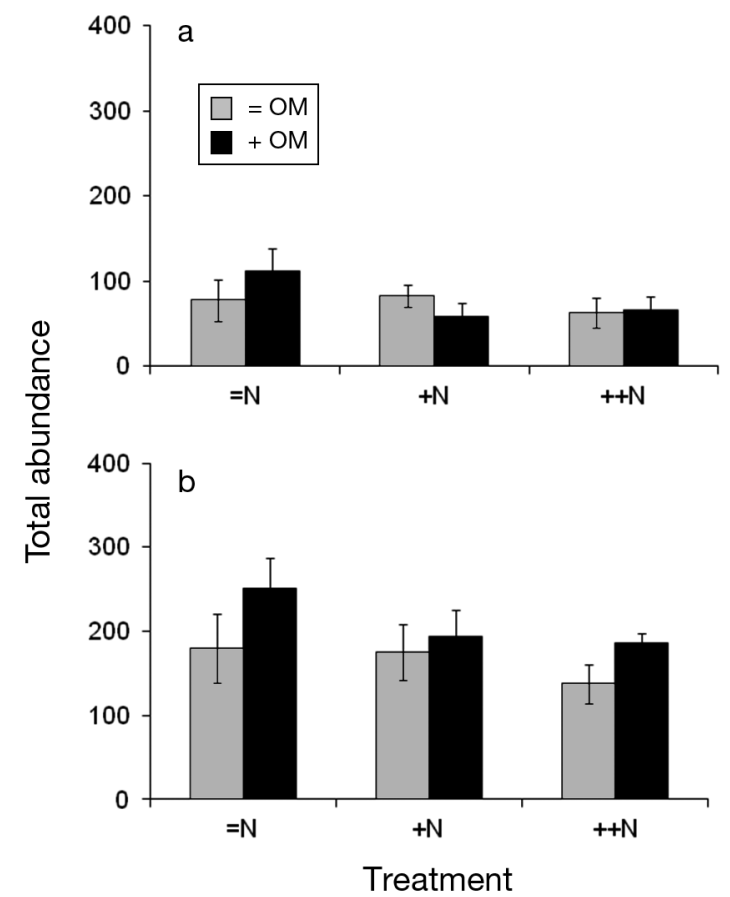

Fig. 3. Mean total abundance of benthic macrofauna $\left( \pm \mathrm{SE}_{;} \mathrm{n}=4\right)$ after (a) 3 mo and (b) $11 \mathrm{mo}$. See Table 3 for abbreviations

Bad ES (Table 6). This pattern of reduced ES in organic matter only and high nutrients with organic matter additions reflects changes in total abundance of macrofauna (Fig. 3), which were underpinned by Capitella sp. in univariate analysis (Table 4).

M-AMBI EQR was significantly reduced by organic matter across all levels of nutrient addition at

Table 5. ANOVAs of differences among biotic indices for AZTI Marine Biotic Index (AMBI) (data untransformed, Cochran's $C=0.3543, \mathrm{p}<0.05$ ) and Multivariate AMBI (MAMBI) (data untransformed, Cochran's $C=0.2632, \mathrm{p}<0.05$ ). ${ }^{* *}$ Significant at $\mathrm{p}<0.01$

\begin{tabular}{|c|c|c|c|c|c|}
\hline \multirow{2}{*}{$\begin{array}{l}\text { Source of } \\
\text { variation }\end{array}$} & \multirow[t]{2}{*}{ df } & \multicolumn{2}{|c|}{ AMBI } & \multicolumn{2}{|c|}{ M-AMBI } \\
\hline & & MS & $F$ & MS & $F$ \\
\hline Time (Ti) & 1 & 0.531 & $5.13^{\mathrm{a}}$ & 0.563 & $1.12^{\mathrm{b}}$ \\
\hline Nutrients (Nu) & 2 & 0.008 & 0.03 & 0.016 & 0.31 \\
\hline $\begin{array}{l}\text { Organic matter } \\
(\mathrm{Om})\end{array}$ & 1 & 1.111 & $11.10^{\mathrm{a}, * *}$ & 0.421 & $23.27^{b_{1 * *}}$ \\
\hline $\mathrm{Ti} \times \mathrm{Nu}$ & 2 & 0.272 & $2.72^{\mathrm{a}}$ & 0.051 & $2.87^{\mathrm{b}}$ \\
\hline $\mathrm{Ti} \times \mathrm{Om}(a)$ & 1 & 0.023 & $0.23^{\mathrm{a}}$ & 0.003 & $0.17^{b}$ \\
\hline $\mathrm{Nu} \times \mathrm{Om}$ & 2 & 0.001 & $0.02^{\mathrm{a}}$ & 0.003 & 0.12 \\
\hline $\mathrm{Ti} \times \mathrm{Nu} \times \mathrm{Om}(b)$ & 2 & 0.071 & $0.71^{\mathrm{a}}$ & 0.026 & $1.49^{\mathrm{b}}$ \\
\hline Residual (C) & 36 & 0.103 & & 0.018 & \\
\hline \multicolumn{6}{|c|}{$\begin{array}{l}{ }^{\mathrm{a}} F \text { calculated over pooled MS }(a+b+c)=0.100 \text { with } \\
39 \mathrm{df} \\
{ }^{\mathrm{b}} F \text { calculated over pooled MS }(b+c)=0.0181 \text { with } \\
37 \mathrm{df}\end{array}$} \\
\hline
\end{tabular}

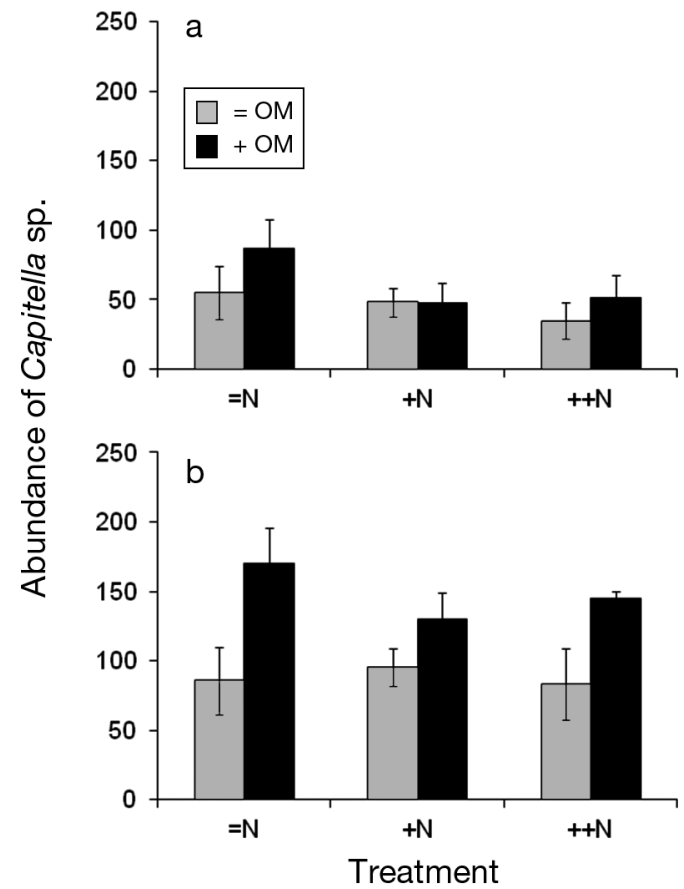

Fig. 4. Mean abundance of Capitella sp. $( \pm \mathrm{SE} ; \mathrm{n}=4)$ after (a) 3 mo and (b) 11 mo. See Table 3 for abbreviations

both sampling times (Table 5), although this was not consistently translated into ES. M-AMBI was able to discriminate between treatments with and without organic matter addition at ambient and medium nutrient additions after $3 \mathrm{mo}$, assigning a lower ES to those with organic matter than those without

Table 6. Ecological status (ES) and biotic index score calculated for treatments after 3 and 11 mo of treatment application by the (a) AZTI Marine Biotic Index (AMBI) and (b) Multivariate AMBI (M-AMBI). See Table 3 for treatment abbreviations

\begin{tabular}{|c|c|c|c|c|}
\hline \multirow[t]{2}{*}{ Treatment } & \multicolumn{2}{|c|}{$3 \mathrm{mo}$} & \multicolumn{2}{|c|}{$11 \mathrm{mo}$} \\
\hline & ES & Score & ES & Score \\
\hline \multicolumn{5}{|l|}{ AMBI } \\
\hline$=\mathrm{N}=\mathrm{OM}$ & Bad & 5.6 & Poor & 4.9 \\
\hline$=\mathrm{N}+\mathrm{OM}$ & Bad & 5.8 & Bad & 5.5 \\
\hline$+\mathrm{N}=\mathrm{OM}$ & Bad & 5.6 & Poor & 5.2 \\
\hline$+\mathrm{N}+\mathrm{OM}$ & Bad & 5.8 & Poor & 5.4 \\
\hline$++\mathrm{N}=\mathrm{OM}$ & Bad & 5.7 & Poor & 5.4 \\
\hline$++\mathrm{N}+\mathrm{OM}$ & Bad & 5.6 & Bad & 5.6 \\
\hline \multicolumn{5}{|l|}{ M-AMBI } \\
\hline$=\mathrm{N}=\mathrm{OM}$ & Moderate & 0.54 & Good & 0.82 \\
\hline$=\mathrm{N}+\mathrm{OM}$ & Poor & 0.38 & Good & 0.63 \\
\hline$+\mathrm{N}=\mathrm{OM}$ & Good & 0.62 & Good & 0.75 \\
\hline$+\mathrm{N}+\mathrm{OM}$ & Poor & 0.31 & Moderate & 0.53 \\
\hline$++\mathrm{N}=\mathrm{OM}$ & Moderate & 0.48 & Good & 0.63 \\
\hline$++\mathrm{N}+\mathrm{OM}$ & Moderate & 0.45 & Moderate & 0.49 \\
\hline
\end{tabular}


(Table 6). At $11 \mathrm{mo}$, treatments with ambient nutrients with and without organic matter additions were assigned Good ES. At medium and high levels of nutrients, addition of organic matter caused a decrease in ES from Good (acceptable) to Moderate (unacceptable) (Table 6).

\section{DISCUSSION}

Faunal responses to organic enrichment followed well-established patterns, with increased abundance of macrofauna, and decreased taxon richness and diversity (Pearson \& Rosenberg 1978, Vetter 1996, Lu \& Wu 1998, Gray et al. 2002, Johnston \& Roberts 2009). Increases in the abundance of the small opportunistic polychaete Capitella sp. underpinned changes in the calculation of biotic indices caused by organic enrichment. Nutrient addition mediated the response of Capitella sp. to organic enrichment. AMBI and M-AMBI responded to organic matter addition, although this response was not consistent over time and was affected by nutrient additions. The opportunistic response of the polychaete Capitella sp. to organic matter was likely to affect the calculation of these indices in the low-diversity systems studied. It is interesting to note that the detection of multiple stressor effects by the indices was only apparent after 11 mo (that is, the ES assigned to multiple-stressor treatments was lower than that assigned to single-stressor and control treatments after 11 mo in all multiple-stressor treatments, although this was not the case after $3 \mathrm{mo}$ ), highlighting the potential importance of long-term field experimentation to obtain ecologically realistic responses. The reduction of large quantities of ecological data into a single value can also result in the loss of valuable ecological information, and this must be considered when interpreting ES. Overall increases in taxon richness and Shannon diversity during the period from 3 to 11 mo may be explained by seasonal changes in the benthic macrofaunal community, although both sampling times were during the summer season (Frid et al. 2009a,b). Another possible explanation for these increases may be the colonisation of treated plots following recruitment, or migration of generalist feeders from surrounding sediments to feed on increased detritus or prey on small opportunistic fauna (O'Gorman et al. 2012). Time lags between the initial cause and expression of multiple stressor effects can be long and context-dependent (Adams 2005). Furthermore, M-AMBI, which integrates measures of biodiversity into its calcula- tion, responded to multiple stressors (in both medium and high nutrient treatments with organic matter additions), showing that the inclusion of these measures may lead to detection of patterns not identified by analysing univariate measures alone (Dauvin et al. 2007).

The present study is the first study to experimentally test biotic indices against known inputs of multiple stressors in intertidal habitats. There was a gradient of increasing nutrients in surface and pore water with increased nutrient inputs, and while organic matter additions did alter levels of both ammonia and nitrate, these changes were not significant. The intertidal site and open nature of the plots prevent assessment of nutrient levels against chemical status, which is given for pelagic waters in the WFD. Although organic enrichment was undoubtedly imposed on the relevant plots, increased levels of organic matter could not be detected by loss on ignition. However, faunal responses were typical of organically enriched sediments, with increases in large nematodes and opportunist polychaetes such as Capitella sp. (Pearson \& Rosenberg 1978). Addition of nutrients and organic matter to experimental plots often results in inconsistent increases of nutrients and organic matter in sediments (e.g. Vetter \& Dayton 1999, Rossi \& Underwood 2002, Rossi 2003, 2006, McClanahan et al. 2005, Callier et al. 2009). Organic matter is rapidly assimilated in sedimentary systems and its uptake can be accelerated by increased microbial activity caused by nutrients (Vetter 1996, Rossi 2006). Vertical distribution, and therefore measurements, of organic matter may have been influenced by macrofaunal bioturbation activity and recycling of the organic fraction in metabolic activities (Callier et al. 2009, Sundbäck et al. 2010). Furthermore, increased reducing conditions can cause the rapid assimilation of nutrients and organic matter and increased nutrients in pore water (Perez et al. 2007). The experimental addition of organic matter did cause measurable effects in the present experiment, but the process by which it did so must have been mediated by rapid uptake of the material by the microscopic and macroscopic biota. It is also possible that some of the added nutrients and organic matter was washed away by the tides, although nutrient sticks were observed to be retained in the sediments. The mechanisms through which observed effects of treatments on macrofaunal communities would arise are likely indirect, via reduced oxygen conditions in the sediments leading to brief periods of anoxia. Increased organic matter coupled with anoxia can cause changes in the redox conditions in the sedi- 
ments, leading to increased production of sulphides from anaerobic decomposition (Risgaard-Petersen 2003), Furthermore, any reduction in oxygen levels would most likely be caused by increased microbial respiration, stimulated through the addition of labile organic matter, which is likely a readily available food source for microbiota (Fitch \& Crowe 2011). This reduction in oxygen levels can have a corresponding effect on macrofauna, leading to opportunities for taxa tolerant of such conditions, such as Capitella sp., to increase in abundance. Nutrients added in this experiment are not labile to the same extent as organic matter, and do not directly lead to reduced oxygen conditions (Fitch \& Crowe 2011). In order for nutrients to affect macrofauna, the pathway is perhaps more indirect and over a longer timescale via increases in primary production (by e.g. benthic diatoms). The likelihood of nutrients acting along a more indirect pathway may go some way to explaining the observed changes in diversity over time.

The response of the AMBI and M-AMBI indices to organic matter was not surprising given that they are based on the model of macrofaunal succession following a gradient of organic enrichment described by Pearson \& Rosenberg (1978). The faunal composition in experimental plots changes from natural conditions, with a shift from dominance of large species such as Arenicola marina to small opportunistic taxa such as Capitella sp. (Fitch \& Crowe 2010). Previous studies have, however, indicated that they may not be reliable monitoring tools in intertidal habitats (Blanchet et al. 2008, Bouchet \& Sauriau 2008, Fitch \& Crowe 2010), although this is not always the case (Borja et al. 2009b). AMBI can be influenced by sampling effort (Grémare et al. 2009), and a high bias can be observed when ES is calculated for samples with low taxon richness and number of individuals (Dauvin et al. 2010). The small area sampled in this instance may have caused a bias in the classification of ES relative to the original methodology, as fewer individuals would have been sampled (Muxika et al. 2007b). As such, whilst the actual calculated values are comparable, caution must be advised when interpreting ES (Muxika et al. 2007a). Recalibration of boundary thresholds between ES for different habitats and stress regimes may be required to prevent areas appearing more (or less) perturbed than they really are (Ruellet \& Dauvin 2007, Blanchet et al. 2008). Capitella sp. is a widely recognised indicator taxon with a well documented response to organic enrichment (Pearson \& Rosenberg 1978). However, it has previously been shown to exhibit a variable response over small and large temporal scales
(Bustos-Baez \& Frid 2003, Fitch \& Crowe 2010). The interactive effect of the 2 closely associated stressors, inorganic nutrients and organic matter, on abundance of Capitella sp. highlights that its responses to multiple stressors are somewhat unpredictable. This further undermines its utility as a bioindicator. The mechanisms that were responsible for the measurable faunal response to organic enrichment at the lowest and highest level of nutrient enrichment but not the medium level remain unclear.

The processes initiated by nutrient enrichment, which can negate competition for food by increasing organic matter, may go some way to explaining observed interactive effects of multiple stressors (Thrush et al. 2008). Responses of benthic macrofauna to organic enrichment are well documented, but these effects are likely to be caused by interactions among many factors, rather than by any single factor (Gray et al. 2002, Thrush et al. 2008). Nutrients have been to shown to lead to both synergism and antagonism when interacting with a variety of negative stressors such as toxins (Crain et al. 2008, Sundbäck et al. 2010) and intrinsic factors such as predation (Posey et al. 2006). These phenomena require further research, particularly given that inputs of inorganic nutrients and organic matter are often simultaneous and of varying relative concentrations (Lenihan et al. 2003).

\section{CONCLUSIONS}

Understanding the effects of multiple stressors is vital for the effective targeted management of coastal ecosystems (Klug \& Cottingham 2001, Ban et al. 2010). The response of ecosystems to multiple stressors can be difficult to predict and detect, as interactions can be complex (Folt et al. 1999, Klug \& Cottingham 2001, Thrush et al. 2008, Statzner \& Che 2010) and site-specific (Whomersley et al. 2010). The present study contributes to existing data in the characterisation of the effects of multiple stressors on intertidal macrofauna and the development and testing of effective monitoring tools. The complex interactive effects of nutrients and organic matter had not been previously characterised. The interaction was revealed in the unpredictable response of the key 'indicator' taxon Capitella sp. to different combinations of nutrients and organic matter. Some indices will compensate for the responses of individual taxa to stressor effects through the incorporation of other measures of diversity in their calculation (Dauvin et al. 2007). Capitella sp. was, however, likely to be 
influential in the assessment of ES, highlighting the need for a degree of caution in the interpretation of environmental status based on environmental indicators when complex biological responses are involved.

Acknowledgements. This work was funded by a UCD Ad Astra scholarship to J.E.F. and received support through collaboration with BioChange: Biodiversity and Environmental Change, an Integrated Study Encompassing a Range of Scales, Taxa and Habitats (project code 2005-CD-B2_MI) funded by the Environmental Protection Agency under the Strive Programme 2007-2013. We are grateful to J. Coughlan for technical and laboratory assistance; A. Cahill, C. Fitzroy and J. Kochmann for help in the field; and C. L. J. Frid, E. J. O'Gorman and 3 anonymous referees, who provided valuable comments on an earlier draft.

\section{LITERATURE CITED}

Adams SM (2005) Assessing cause and effect of multiple stressors on marine systems. Mar Pollut Bull 51:649-657

Bald J, Borja A, Muxika I, Franco J, Valencia V (2005) Assessing reference conditions and physico-chemical status according to the European Water Framework Directive: a case-study from the Basque Country (Northern Spain). Mar Pollut Bull 50:1508-1522

> Ban NC, Alidina HM, Ardron JA (2010) Cumulative impact mapping: advances, relevance and limitations to marine management and conservation, using Canada's Pacific waters as a case study. Mar Policy 34:876-886

> Blanchet H, Lavesque N, Ruellet T, Dauvin JC and others (2008) Use of biotic indices in semi-enclosed coastal ecosystems and transitional waters habitats-implications for the implementation of the European Water Framework Directive. Ecol Indic 8:360-372

> Borja A, Franco J, Perez V (2000) A marine Biotic Index to establish the ecological quality of soft-bottom benthos within European estuarine and coastal environments. Mar Pollut Bull 40:1100-1114

Borja A, Muxika I, Franco J (2003) The application of a Marine Biotic Index to different impact sources affecting softbottom benthic communities along European coasts. Mar Pollut Bull 46:835-845

Borja A, Muxika I, Franco J (2006) Long-term recovery of soft-bottom benthos following urban and industrial sewage treatment in the Nervión estuary (southern Bay of Biscay). Mar Ecol Prog Ser 313:43-55

Borja A, Josefson AB, Miles A, Muxika I and others (2007) An approach to the intercalibration of benthic ecological status assessment in the North Atlantic ecoregion, according to the European Water Framework Directive. Mar Pollut Bull 55:42-52

Borja A, Bricker SB, Dauer DM, Demetriades NT and others (2008) Overview of integrative tools and methods in assessing ecological integrity in estuarine and coastal systems worldwide. Mar Pollut Bull 56:1519-1537

> Borja A, Miles A, Occhipinti-Ambrogi A, Berg T (2009a) Current status of macroinvertebrate methods used for assessing the quality of European marine waters: implementing the Water Framework Directive. Hydrobiologia 633:181-196

- Borja A, Muxika I, Rodriguez JG (2009b) Paradigmatic responses of marine benthic communities to different anthropogenic pressures, using M-AMBI, within the European Water Framework Directive. PSZNI Mar Ecol 30:214-227

Bouchet VMP, Sauriau PG (2008) Influence of oyster culture practices and environmental conditions on the ecological status of intertidal mudflats in the Pertuis Charentais (SW France): a multi-index approach. Mar Pollut Bull 56: 1898-1912

> Bustos-Baez S, Frid C (2003) Using indicator species to assess the state of macrobenthic communities. Hydrobiologia 496:299-309

- Callier MD, Richard M, McKindsey CW, Archambault P, Desrosiers G (2009) Responses of benthic macrofauna and biogeochemical fluxes to various levels of mussel biodeposition: an in situ 'benthocosm' experiment. Mar Pollut Bull 58:1544-1553

> Carreiro-Silva M, McClanahan TR, Kiene WE (2009) Effects of inorganic nutrients and organic matter on microbial euendolithic community composition and microbioerosion rates. Mar Ecol Prog Ser 392:1-15

Ceccherelli G, Cinelli F (1997) Short-term effects of nutrient enrichment of the sediment and interactions between the seagrass Cymodocea nodosa and the introduced green alga Caulerpa taxifolia in a Mediterranean bay. J Exp Mar Biol Ecol 217:165-177

Claudet J, Fraschetti S (2010) Human-driven impacts on marine habitats: a regional meta-analysis in the Mediterranean Sea. Biol Conserv 143:2195-2206

Crain CM, Kroeker K, Halpern BS (2008) Interactive and cumulative effects of multiple human stressors in marine systems. Ecol Lett 11:1304-1315

> Dauvin JC (2007) Paradox of estuarine quality: benthic indicators and indices, consensus or debate for the future. Mar Pollut Bull 55:271-281

> Dauvin JC, Ruellet T (2007) Polychaete/amphipod ratio revisited. Mar Pollut Bull 55:215-224

> Dauvin JC, Ruellet T, Desroy N, Janson AL (2007) The ecological quality status of the Bay of Seine and the Seine estuary: use of biotic indices. Mar Pollut Bull 55:241-257

> Dauvin JC, Bellan G, Bellan-Santini D (2010) Benthic indicators: from subjectivity to objectivity - where is the line? Mar Pollut Bull 60:947-953

> Diaz RJ, Solan M, Valente RM (2004) A review of approaches for classifying benthic habitats and evaluating habitat quality. J Environ Manag 73:165-181

Fitch JE, Crowe TP (2010) Effective methods for assessing ecological quality in intertidal soft-sediment habitats. Mar Pollut Bull 60:1726-1733

Fitch JE, Crowe TP (2011) Combined effects of temperature, inorganic nutrients and organic matter on ecosystem processes in intertidal sediments. J Exp Mar Biol Ecol 400:257-263

> Fleischer D, Grémare A, Labrune C, Rumohr H, Berghe EV, Zettler ML (2007) Performance comparison of two biotic indices measuring the ecological status of water bodies in the Southern Baltic and Gulf of Lions. Mar Pollut Bull 54:1598-1606

> Folt CL, Chen CY, Moore MV, Burnaford J (1999) Synergism and antagonism among multiple stressors. Limnol Oceanogr 44:864-877

> Frid CLJ, Garwood PR, Robinson LA (2009a) The North Sea benthic system: a 36 year time-series. J Mar Biol Assoc UK 89:1-10

Frid CLJ, Garwood PR, Robinson LA (2009b) Observing change in a North Sea benthic system: a 33 year time 
series. J Mar Syst 77:227-236

Gray JS, Wu RS, Or YY (2002) Effects of hypoxia and organic enrichment on the coastal marine environment. Mar Ecol Prog Ser 238:249-279

> Grebmeier JM, McRoy CP, Feder HM (1988) Pelagicbenthic coupling on the shelf of the northern Bering and Chukchi Seas. I. Food supply source and benthic biomass. Mar Ecol Prog Ser 48:57-67

> Grémare A, Labrune C, Vanden Berghe E, Amouroux JM and others (2009) Comparison of the performances of two biotic indices based on the MacroBen database. Mar Ecol Prog Ser 382:297-311

> Halpern BS, McLeod KL, Rosenberg AA, Crowder LB (2008) Managing for cumulative impacts in ecosystem-based management through ocean zoning. Ocean Coast Manag 51:203-211

HiMOM (2005) Hierarchical monitoring methods. European Commission Fifth Framework Programme. Contract: EVK3-CT-2001-00052. Brockman Consult, Geesthacht

> Ibarra-Obando SE, Heck KL, Spitzer PM (2004) Effects of simultaneous changes in light, nutrients, and herbivory levels, on the structure and function of a subtropical turtlegrass meadow. J Exp Mar Biol Ecol 301:193-224

Johnston EL, Roberts DA (2009) Contaminants reduce the richness and evenness of marine communities: a review and meta-analysis. Environ Pollut 157:1745-1752

> Jones D, Frid CLJ (2009) Altering intertidal sediment topography: effects on biodiversity and ecosystem functioning. PSZNI Mar Ecol 30(Suppl 1):83-96

> Klug JL, Cottingham KL (2001) Interactions among environmental drivers: community responses to changing nutrients and dissolved organic carbon. Ecology 82: 3390-3403

Koch MS, Schopmeyer S, Kyhn-Hansen C, Madden CJ (2007) Synergistic effects of high temperature and sulfide on tropical seagrass. J Exp Mar Biol Ecol 341:91-101

> Larson F, Petersen DG, Dahllöf I, Sundbäck K (2007) Combined effects of an antifouling biocide and nutrient status on a shallow-water microbenthic community. Aquat Microb Ecol 48:277-294

> Lenihan HS, Peterson CH, Kim SL, Conlan KE and others (2003) Variation in marine benthic community composition allows discrimination of multiple stressors. Mar Ecol Prog Ser 261:63-73

Lopez NI, Duarte CM, Vallespinos F, Romero J, Alcoverro T (1998) The effect of nutrient additions on bacterial activity in seagrass (Posidonia oceanica) sediments. J Exp Mar Biol Ecol 224:155-166

Loureiro S, Newton A, Icely J (2006) Boundary conditions for the European Water Framework Directive in the Ria Formosa lagoon, Portugal (physico-chemical and phytoplankton quality elements). Estuar Coast Shelf Sci 67: 382-398

Lu L, Wu RSS (1998) Recolonization and succession of marine macrobenthos in organic-enriched sediment deposited from fish farms. Environ Pollut 101:241-251

Maloney J (1996) Influence of organic enrichment on the partitioning and bioavailability of cadmium in a microcosm study. Mar Ecol Prog Ser 144:147-161

McClanahan TR, Steneck RS, Pietri D, Cokos B, Jones S (2005) Interaction between inorganic nutrients and organic matter in controlling coral reef communities in Glovers Reef Belize. Mar Pollut Bull 50:566-575

Muxika I, Borja A, Bonne W (2005) The suitability of the marine biotic index (AMBI) to new impact sources along
European coasts. Ecol Indic 5:19-31

> Muxika I, Borja A, Bald J (2007a) Using historical data, expert judgement and multivariate analysis in assessing reference conditions and benthic ecological status, according to the European Water Framework Directive. Mar Pollut Bull 55:16-29

Muxika I, Ibaibarriaga L, Sáiz JI, Borja A (2007b) Minimal sampling requirements for a precise assessment of softbottom macrobenthic communities, using AMBI. J Exp Mar Biol Ecol 349:323-333

Nayar S, Miller D, Bryars S, Cheshire AC (2006) A simple, inexpensive and large volume pore water sampler for sandy and muddy substrates. Estuar Coast Shelf Sci 66: 298-302

O'Gorman EJ, Fitch JE, Crowe TP (2012) Multiple anthropogenic stressors and the structural properties of food webs. Ecology 93:441-448

Pearson TH, Rosenberg R (1978) Macrobenthic succession in relation to organic enrichment and pollution of the marine environment. Oceanogr Mar Biol Annu Rev 16: 229-311

Perez M, Invers O, Ruiz JM, Frederiksen MS, Holmer M (2007) Physiological responses of the seagrass Posidonia oceanica to elevated organic matter content in sediments: an experimental assessment. Exp Mar Biol Ecol 344:149-160

Petersen DG, Sundbäck K, Larson F, Dahllöf I (2009) Pyrene toxicity is affected by the nutrient status of a marine sediment community: implications for risk assessment. Aquat Toxicol 95:37-43

Posey MH, Alphin TD, Cahoon L (2006) Benthic community responses to nutrient enrichment and predator exclusion: influence of background nutrient concentrations and interactive effects. J Exp Mar Biol Ecol 330:105-118

Rice J, Arvanitidis C, Borja A, Frid C and others (2012) Indicators for sea-floor integrity under the European Marine Strategy Framework Directive. Ecol Indic 12:174-184

> Risgaard-Petersen N (2003) Coupled nitrification-denitrification in autotrophic and heterotrophic estuarine sediments: on the influence of benthic microalgae. Limnol Oceanogr 48:93-105

> Rosenberg R, Blomqvist M, Nilsson HC, Cederwall H, Dimming A (2004) Marine quality assessment by use of benthic species-abundance distributions: a proposed new protocol within the European Union Water Framework Directive. Mar Pollut Bull 49:728-739

Rossi F (2003) Short-term response of deposit-feeders to an increase of the nutritive value of the sediment through seasons in an intertidal mudflat (Western Mediterranean, Italy). J Exp Mar Biol Ecol 290:1-17

Rossi F (2006) Small-scale burial of macroalgal detritus in marine sediments: effects of Ulva spp. on the spatial distribution of macrofauna assemblages. Exp Mar Biol Ecol 332:84-95

Rossi F, Underwood AJ (2002) Small-scale disturbance and increased nutrients as influences on intertidal macrobenthic assemblages: experimental burial of wrack in different intertidal environments. Mar Ecol Prog Ser 241: 29-39

> Ruellet T, Dauvin JC (2007) Benthic indicators: analysis of the threshold values of ecological quality classifications for transitional waters. Mar Pollut Bull 54:1707-1714

Simboura N, Zenetos A (2002) Benthic indicators to use in Ecological Quality classification of Mediterranean soft bottom marine ecosystems, including a new Biotic Index. 
Mediterr Mar Sci 3:77-111

Statzner B, Che LA (2010) Can biological invertebrate traits resolve effects of multiple stressors on running water ecosystems? Freshw Biol 55:80-119

Sturgis RB, Murray L (1997) Scaling of nutrient inputs to submersed plant communities: temporal and spatial variations. Mar Ecol Prog Ser 152:89-102

Sundbäck K, Snoeijs P (1991) Effects Of nutrient enrichment on microalgal community composition in a coastal shallow-water sediment system: an experimental study. Bot Mar 34:341-358

Sundbäck K, Petersen DG, Dahllöf I, Larson F (2007) Combined nutrient-toxicant effects on a shallow-water marine sediment system: sensitivity and resilience of ecosystem functions. Mar Ecol Prog Ser 330:13-30

Sundbäck K, Alsterberg C, Larson F (2010) Effects of multiple stressors on marine shallow-water sediments: response of microalgae and meiofauna to nutrienttoxicant exposure. J Exp Mar Biol Ecol 388:39-50

Thrush SF, Hewitt JE, Hickey CW, Kelly S (2008) Multiple stressor effects identified from species abundance distributions: interactions between urban contaminants and species habitat relationships. J Exp Mar Biol Ecol 366: 160-168
Underwood AJ (1997) Experiments in ecology: their logical design and interpretation using analysis of variance, Vol 1. Cambridge University Press, Sydney

Underwood AJ, Chapman MG (1998) GMAV5 for windows. Institute of Marine Ecology, University of Sydney, Australia

$>$ Vetter EW (1995) Detritus-based patches of high secondary production in the nearshore benthos. Mar Ecol Prog Ser 120:251-262

Vetter EW (1996) Enrichment experiments and infaunal population cycles on a Southern California sand plain: response of the leptostracan Nebalia daytoni and other infauna. Mar Ecol Prog Ser 137:83-93

Vetter EW, Dayton PK (1999) Organic enrichment by macrophyte detritus, and abundance patterns of megafaunal populations in submarine canyons. Mar Ecol Prog Ser 186:137-148

Warwick RM, Clarke KR, Somerfield PJ (2010) Exploring the marine biotic index (AMBI): variations on a theme by Angel Borja. Mar Pollut Bull 60:554-559

Whomersley P, Huxham M, Bolam S, Schratzberger M, Augley J, Ridland D (2010) Response of intertidal macrofauna to multiple disturbance types and intensities - an experimental approach. Mar Environ Res 69:297-308

Appendix 1. Additional data describing the results of the procedural control analysis, a list of taxa identified across all experimental plots and mean organic matter measured in each treatment

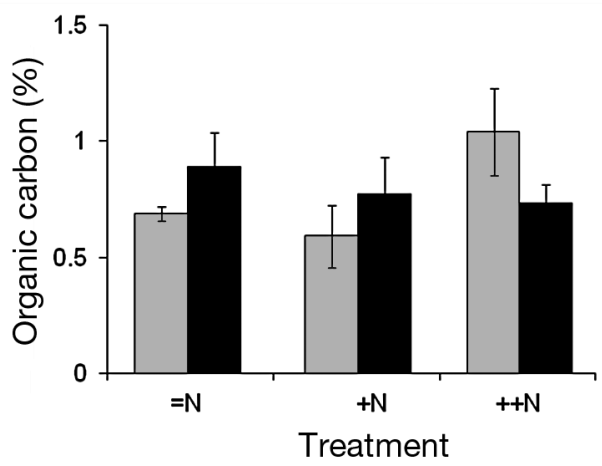

Fig. A1. Mean organic matter content $( \pm \mathrm{SE}$; $\mathrm{n}=4$ ). See Table 3 for abbreviations

Table A1. ANOVAs of differences among procedures. Time (2 levels: 3 and $11 \mathrm{mo}$ ); Treatment (3 levels: high, medium and ambient nutrients with organic matter addition); Procedure (3 levels: treatment applied, procedural control, and unmanipulated control). $S$ : taxon richness, $H^{\prime}$ : Shannon index, $N$ : total abundance. ${ }^{* *}$ Significant at $\mathrm{p}<0.01$

\begin{tabular}{|c|c|c|c|c|c|c|c|}
\hline \multirow{2}{*}{$\begin{array}{l}\text { Source of } \\
\text { variation }\end{array}$} & \multirow[t]{2}{*}{ df } & \multicolumn{2}{|r|}{$S$} & \multicolumn{2}{|c|}{$H^{\prime}$} & \multicolumn{2}{|c|}{$N$} \\
\hline & & MS & $F$ & MS & F & MS & $F$ \\
\hline Time (Ti) & 1 & 11.57 & 5.95 & 0.34 & 5.63 & 5280.66 & 2.11 \\
\hline Treatment $(\mathrm{Tr})$ & 2 & 2.72 & 0.04 & 0.11 & 0.15 & 306.18 & 0.04 \\
\hline Procedure (Pr) & 2 & 10.05 & 14.68 & 0.38 & 5.97 & 10083.19 & 1.22 \\
\hline $\operatorname{Ti} \times \operatorname{Tr}$ & 2 & 76.35 & $39.27^{* *}$ & 0.72 & $12.24^{* *}$ & 78476.22 & 31.33 \\
\hline $\mathrm{Ti} \times \operatorname{Pr}$ & 2 & 0.68 & 0.35 & 0.06 & 1.08 & 8270.89 & $3.30^{\mathrm{a}, * *}$ \\
\hline $\operatorname{Tr} \times \operatorname{Pr}$ & 4 & 2.02 & 1.31 & 0.03 & 0.31 & 1318.96 & 2.44 \\
\hline $\operatorname{Ti} \times \operatorname{Tr} \times \operatorname{Pr}$ & 4 & 1.54 & 0.08 & 0.01 & 1.74 & 540.77 & 0.22 \\
\hline Residual & 36 & 1.94 & & 0.06 & & 2504.56 & \\
\hline
\end{tabular}

Table A2. List of taxa identified from experimental plots

\begin{tabular}{|llll|}
\hline Ampithoe sp. & Crangon crangon & Heteromastus filiformis & Phyllodoce sp. \\
Angulus tenuis & Eteone (flava) foliosa & Hydrobia ulvae & Pygospio elegans \\
Arenicola marina & Fabriciola sp. & Macoma balthica & Scoloplos armiger \\
Capitella sp. & Gammarus sp. & Malacoceros vulgaris & Spionid sp. \\
Carcinus maenas & Glycera sp. & Nematoda & Tubificoides benedii \\
Cerastoderma edule & Harmothoe sp. & Nephtys hombergii & \\
Corophium volutator & Harpacticoida & Nereis diversicolor & \\
\hline
\end{tabular}

